\title{
A satisfaction survey of international master students' cultivation management in China and some reform proposals —-Taking Dalian University of Technology as an example
}

\author{
Xincheng Zhu ${ }^{1, a,{ }^{*},}$ Yunmei Yang ${ }^{2, b}$, Shuai Guo ${ }^{3, \mathrm{c}}$ and Hua Shang ${ }^{4, \mathrm{~d}}$ \\ 1,2,3,4Faculty of Management and Economics, Dalian University of Technology, \\ Dalian, Liaoning, China \\ azxcdut@163.com, b857630310@qq.com, \\ c1019134225@qq.com, dshanghua@dlut.edu.cn \\ ${ }^{*}$ Corresponding author
}

Key words: the master students studying in China, cultivation and management

\begin{abstract}
Under the economic globalization 's environment,international students' cultivation has become an integral part of educational strategies around the world. Furthermore,it has also become an important way to promote the internationalization of higher education in every university.This paper takes the master students studying in Dalian University of Technology as the research target,and it summarizes five core issues through analyzing factors affecting international master students' degree of satisfaction by the empirical research method of questionnaire and interview.Finally, the paper deeply studies the key points of the reform of international students' education management in China,and put forward some scientific and reasonable proposals.
\end{abstract}

\section{来华留学硕士研究生培养管理满意度调查与改革建议 以大连理工大学为例}

\author{
朱新城 ${ }^{1, \mathrm{a}, *}$, 杨运美 ${ }^{2, \mathrm{~b}}$, 郭帅 ${ }^{3, \mathrm{c}}$, 商华 ${ }^{4, \mathrm{~d}}$ \\ ${ }^{1,2,3,4}$ 大连理工大学管理与经济学部, 大连, 辽宁, 中国 \\ azxcdut@163.com, b857630310@qq. com, \\ c1019134225@qq.com, shanghua@dlut.edu.cn
}

关键词: 来华留学硕士研究生、培养管理

摘要. 在经济全球化发展的背景下，国际学生教育已经成为各国教育发展战略中不可或缺的 一部分, 同时也是各高校推动自身高等教育国际化发展进程的重要途径。本文以大连理工大 学来华留学硕士研究生为研究对象, 通过问卷调查的实证研究方法和面对面访谈法, 对硕士 留学生培养进行案例研究, 分析影响来华留学硕士研究生满意度的因素, 提炼出五大核心问 题, 最后进一步深入研究我国高校国际学生培养管理改革的关键突破口, 并相应地提出科学 合理的对策建议。

\section{1. 引言}

研究生教育是我国高等教育的重要组成部分, 在国家现代化建设和知识创新体系中占有 突出的战略地位。研究生教育质量之高低, 在一定程度上影响着一个国家的创新能力, 影响 着国家的综合实力。因此对于留学生教育而言, 来华留学硕士研究生的培养无疑成为重中之 
重。同时我国来华留学生主要由亚非等发展中国家学生组成, 发达国家学生占比较少, 这说 明我国留学生教育事业仍处于初级阶段, 留学生教育改革促发展迫在眉睫, 而硕士留学生必 然成为改革的核心。

大连理工大学作为中国著名的 “四大工学院”之一，国家 “211 工程”、“985 工程” 重 点建设的大学，同时还是 “中俄工科大学联盟”、“中俄交通大学联盟”、“中欧工程教育平台” 的主要成员, 足以可见其在高等教育界的地位。经过近六十年的发展, 大连理工大学的留学 生教育水平已处于全国前列, 所以将其作为来华留学硕士研究生培养现状研究的对象, 在研 究中发现的问题, 对其他同类高校有很好的借鉴意义。

因此, 本文希望通过对大连理工大学硕士留学生培养现状的调查与分析, 识别并归纳来 华留学硕士研究生培养中产生问题的根源, 进而有针对性地提出硕士留学生培养改革的建议, 借以推动大连理工大学硕士留学生教育模式改革, 同时为国内其他高校来华留学生培养管理 体系建设提供参考借鉴，从制度和管理层面推进留学生培养模式的改革与实践。

\section{2. 大连理工大学来华留学硕士研究生培养管理现状}

大连理工大学的留学生教育开始于上个世纪六十年代, 截止目前已经接收了 100 多个国 家的 8000 多名国际学生来校学习, 其中 2015 年度在校留学生中硕士生及博士生总人数为 548 人。留学生教育已经成为大连理工大学国际化发展的重要前提, 同时也是提高学校综合 实力和国际化影响力的有效途径。

\section{1 生源分布的全球化}

2015 年大连理工大学在校研究生留学生共 548 人, 分别来自 73 个国家, 38.0\%来自亚 洲, 其中巴基斯坦籍人数最多, 共 102 人; $19.5 \%$ 来自非洲; $17.0 \%$ 来自欧洲, 其中以东欧国 家为主。由此可以看出, 大多数留学生来自发展中国家, 这些国家与中国相比, 经济较为落 后, 教育水平有限, 因而中国稳定的政治环境、高速发展中的经济趋势、不断进步创新的科 学技术和中国政府在来华留学生方面的各种吸引政策, 成为留学选择目的地中的极佳选择。

\section{2 学习专业的多样化}

大连理工大学来华留学硕士研究生学习专业数量呈逐年递增的趋势, 所学学科逐渐丰富 化, 且留学生人数渐渐向各个学科分散均衡。2007年前后大连理工大学来华留学硕士研究生 完全由语言类学生组成, 直至 2010 年左右逐渐出现其他学科专业学生。从 2010 年至 2015 年, 管理经济类专业的学生逐渐成为来华留学硕士研究生的主力军, 且基本占到总人数的 $50 \%$ 左右, 语言类学生占比逐渐下降, 但是其他学科专业学生占比逐年上升。总而言之, 这不仅 表明了来我校学习的留学生学习专业的多样性, 还进一步证明了我校学科建设的综合性。

\section{3 校园文化的多元化}

来自不同国家、不同民族的每一位留学生都有着不同的文化背景, 大连理工大学来自全 球 73 个国家各个民族的来华留学生自然而然地形成了丰富多元的文化环境。我校高度重视 促进多元文化的融合与交流, 每年都会举办多次文化交流活动, 不仅丰富了学生的课余生活, 还促进了留学生与中国学生之间的交融。

综上所述, 正是因为来华留学硕士研究生生源分布的全球化, 学习专业的多样化, 校园 文化的多元化, 才形成了硕士留学生培养的挑战性, 在硕士留学生培养管理过程中, 除了不 断吸收学习他校的优秀经验, 还应该积极加强学校与学生之间的信息反馈, 努力了解硕士留 学生的满意度, 从学生们的意见中不断改革完善培养体系。 


\section{3. 大连理工大学来华留学硕士研究生培养管理现状调查及分析}

本文将以大连理工大学为例, 通过对大连理工大学在校硕士留学生的满意度调查, 发现 培养管理中的问题, 并相对应地提出合理的建议。为了真实有效地了解来华留学硕士研究生 的满意度, 我们向 216 名在校来华留学硕士研究生（不包括语言生）发放了纸质或者电子版 的调查问卷, 最终成功回收 197 份, 其中有效问卷 185 份, 问卷回收率 91.2\%, 问卷有效率 93.9\%。

通过对 185 份有效问卷数据的聚类分析、相关性分析及马科维茨均值方差分析，找出了 影响留学生满意度的 9 大因素。随后对 9 个因素做因子分析, 降低维度, 选取最优 7 个因子, 成功地发现了影响留学生满意度的 7 个关键影响因素, 分别为: 教学过程中师生进行互助沟 通、课程设置合理、组织留学生社会实践活动、团队合作能力得到加强、创新、创业能力得 到发展、教师注重对学生能力的培养、结交本土同学。

\section{1 聚类分析}

\section{1.1 聚类变量的选择}

从问卷量表的 “学生期望与感受、教学服务、教学方式、人际关系、课外活动、校园生 活、管理支持、自我发展、奖惩制度” 9 个类别的问题入手, 将每一类问题的问卷结果制作 成折线图，选取折线图所示结果中波动较大的子问题作为这一大类问题的代表找出 9 个关键 因素, 充当聚类变量各类问题。最终选择为聚类分析的变量分别为: 留学生入学后对学校教 育服务质量的整体感受、课程设置的合理性、教学过程中师生进行互动与沟通、是否结交了 本土同学、组织留学生进行社会实践活动、行政人员的服务质量、团结合作能力、创新创业 能力得到发展、了解学校各种规章制度。

3. 1.2 系统聚类

选取上文确定的九项指标作为聚类变量, 通过系统聚类, 确定将问卷调查的留学生分为 三类。三类留学生的特性为: 第一类留学生对学校的培养体系、课程设置、软硬件配置均较 为满意; 第二类留学生除结交了中国本土同学外, 其他问题的满意度为均较低水平, 第三类 留学生的各项满意度为中等水平。

\section{3. $1.3 \mathrm{~K}$-means 聚类}

对系统聚类结果进行分析后, 将留学生划分成为三类, 再通过k-means聚类方法得到聚 类中心, 对聚类结果的可靠性进一步进行检验。对k-means检验结果进行分析可知: 三类重 心距离较大, 各类别留学生特点较为明显, 因此可验证系统聚类将问卷调查的留学生划分为 三类是合理的。

\subsection{4 聚类结果分析}

通过上述系统聚类及k-means聚类检验得到的结果，最终可以将参与李克特量表问卷调 查的留学生划分为三类, 满意度较高的有 73 人, 比例为 $33 \%$, 即对十个类别的指标的满意度 都为大于等于 4 , 满意度中等和较低的共有 112 人, 比例为 $67 \%$, 即对十个类别的指标满意度 都小于等于三。

上述分析说明留学生对学校针对留学生的培养体系的满意度处于中下等水平比例大, 由 此可见, 我校留学生的培养工作还有待于加强; 其次利于后期利用马科维茨均值方差组合模 型分析, 着重对满意度中低等的数据来源进行进一步分析, 找出影响满意度的关键因素。

\section{2 马科维茨均值方差组合模型}

为充分挖掘影响留学生满意度水平高低的因素, 我们对均值-方差模型进行改善, 并使 用改善后的模型对满意度水平为中等及低下的留学生进行深入分析, 确定影响留学生满意度 的 9 项关键指标。将满意度相关性进行升序排列, 选取前 9 项关键因素。 
表 1 马科维茨均值方差组合模型结果

\begin{tabular}{l|c|c|c|c}
\hline \multicolumn{1}{c|}{ 问题 } & 均值 & 方差 & 中间量 & 相关性 \\
\hline 教学过程中师生进行互助沟通 & 2.94 & 0.71 & 2.06 & 2.88 \\
课程设置合理 & 3.11 & 0.81 & 1.89 & 2.33 \\
组织留学生社会实践活动 & 2.85 & 1.00 & 2.15 & 2.16 \\
团队合作能力得到加强 & 3.77 & 0.67 & 1.23 & 1.82 \\
创新、创业能力得到发展 & 3.35 & 1.04 & 1.65 & 1.59 \\
教师注重对学生能力的培养 & 3.44 & 1.12 & 1.56 & 1.40 \\
结交本土同学 & 3.52 & 1.09 & 1.48 & 1.36 \\
行政管理人员的服务质量 & 3.82 & 0.89 & 1.18 & 1.33 \\
学校制定严格的规章制度 & 4.26 & 0.63 & 0.74 & 1.18 \\
\hline
\end{tabular}

经改进后的均值-方差模型分析后，综合考虑满意度均值和满意度方差两个相互制约的 关系, 使其达到最佳平衡状态, 最终确定影响留学生满意度的Top9关键指标为: 教学过程中 师生进行互助沟通、课程设置合理、组织留学生社会实践活动、团队合作能力得到加强、创 新、创业能力得到发展、教师注重对学生能力的培养、广泛化、结交本土同学、行政管理人 员的服务质量、学校制定严格的规章制度。

\section{3 因子分析}

对变量进行因子分析，减少分析指标的同时，尽量减少云指标包含信息的损失，对所收 集的材料进行全面的分析。

（1）首先对上文（均值-方差模型）选择的 9 项指标进行KMO和Bartlett检验，由分析表 格可知: Sig=0.001<0.05, 所以决绝原假设, 即各项指标之间存在相关性，应做因子分析。

（2）成份得分协方差矩阵：该矩阵为对角矩阵，即选择的7个公共因子相互独立，不具 有相关性，因此可证明因子分析效果良好。

综上, 通过上述分析, 我们最终成功得出 7 个最优因子：教学过程中师生进行互助沟通、 课程设置合理、组织留学生社会实践活动、团队合作能力得到加强、创新、创业能力得到发 展、教师注重对学生能力的培养、结交本土同学。这7个因子对硕士留学生满意度的影响最 为关键, 因此我们的后续研究将据此展开。

\section{4 留学生访谈}

通过以上的问卷调查数据分析, 发现影响大连理工大学来华留学硕士研究生培养管理满 意度的 7 个关键因素。为了深入了解这些关键因素背后的根源性问题，我们在这 185 位参与 问卷调查的硕士留学生中有针对性地选取了 63 位硕士留学生进行面对面访谈, 进一步验证 7 个关键因素提取的合理性，与此同时发现其背后的根源性问题。最后我们成功地验证了 7 个 关键因素的合理性，并发现部分具有代表性的问题，整理如下。

3. 4.1 语言沟通难度大, 师资的国际化程度低。

教学过程中师生进行互助沟通和留学生与中国本土学生结交在很大程度上受到语言能力 的制约。留学生与高校教师的中英文水平都没有达到标准, 导致彼此之间很少主动沟通, 与 此同时授课质量受到影响, 进一步加大了留学生们的理解难度和互动难度。

3. 4.2 知识结构存在断层。

部分硕士留学生表示, 在专业课程学习过程中, 很多知识他们在自己国家学习时从来没 有接触过, 而在中国, 老师们默认这些知识是所有人都已经学会的。这也是他们认为课程设 置不合理的主要原因, 笔者认为这主要是由于教育结构差异性产生的知识结构断层造成的。

3.4 .3 社会实践活动的限制多。

在提及社会实践活动时, 留学生表示与学校的活动开展存在较大的矛盾。体现在很难有 机会和与中国学生一起参与社会实践类活动, 也没有机会与中国学生共同组织开展活动。

3. 4.4 能力提升不够重视。 
留学生们表示在学校期间参加各项比赛或者活动的机会非常有限，不仅团队合作能力很 难得到提升, 自我创新创业能力得到发展的机会也极其有限; 在课堂上, 老师很少注重学生 素质能力的培养, 课堂形式多是知识理论灌输型。留学生们建议学校应该多给学生创造机会, 老师们更加注意课堂学习氛围和学生个性能力的培养。

\section{4. 来华留学硕士研究生培养管理问题分析及对策建议}

基于以上的访谈内容，结合前面问卷结果分析得到的七个关键因素，我们发现了来华留 学硕士研究生培养的五大根源性问题。下面笔者将依次深入分析, 并相对应地提出几点对策 建议, 为大连理工大学的硕士留学生教育管理提供参考, 也为国内其他高校硕士留学生教育 管理提供决策依据。

\section{1 语言能力有待提升, 应提高汉语入学标准加强语言继续教育}

“汉语水平考试”（HSK）作为一项专门用来测试母语为非汉语者的汉语水平的一种标准 化语言测验, 经过二十多年的发展和实施, 发展成为今天的新 HSK 考试。新 HSK 考试的提出 弥补了原 HSK 考试的许多不足，更适应了时代的需要。[1]同时，根据国家教育委员会外事局 发布的《外国留学生来华学习的有关规定》, 来华前未学过汉语或汉语水平达不到专业学习 要求者, 来华后需要学习一至二年基础汉语。学习后, 经考试汉语水平达到规定标准后, 方 可进入专业学习。然而, 据调查了解到, 部分高校为了扩大招生数量, 盲目降低汉语言入学 门槛, 大多数选择新 HSK 四级水平为标准。但是其实新 HSK 四级水平还不能满足留学生进入 大学学习的要求, 尤其是学生写作水平的提高, 对其进入大学学习尤为重要。学生运用汉语 进行写作的能力直接关系到学生课程考试成绩与学位论文的撰写, 更关系到学生能否在中国 拿到毕业证书。[2]

因此各高校应该从长远发展出发，根据自身实际情况来制定入学标准，严格掌控来华留 学生汉语言入学门槛, 切不可盲目扩招, 对于部分汉语言能力较为薄弱的来华留学生, 学校 应该努力组织开展汉语言学科的入学后系统教育, 大力提高留学生们的汉语水平。

\section{2 知识结构存在脱节, 应完善制度加强知识水平测评}

知识是人类在社会实践过程中积累的经验成果及其延伸的系统理论。因此，不同文化底 蕴下的形成的知识结构自然存在差异。特别地, 来华硕士留学生中大多数来自于发展中国家, 并且这些国家的教育水平多数比中国落后, 所以来自这些国家的留学生, 教育的知识结构与 中国相比存在差异性也是必然的, 这也就形成了知识结构脱节问题。当前我国大多数高校都 没有认真重视过这个问题, 向来是留学生们被迫通过自主学习来弥补这个缺陷, 这使得他们 在面对专业知识的后续学习时，需要很长的适应期，并且学习难度也大大加大。

所以各高校应该完善招生制度，从源头把好生源质量的关口，在招生过程中，加强对留 学生知识水平的测评, 严格把控来华留学生知识水平, 从生源质量上缩小由于不同文化背景 下知识结构的差异性造成的知识断层，使之与国内教育标准相匹配。

\section{3 个性培养不够重视，应纠正教育意识形态丰富个性化课程设置}

在访谈过程中, 很多留学生都反映道学校的培养体系过分呆板化, 缺乏对学生的个性培 养, 很多老师上课过程中, 课堂氛围很凝重, 缺乏活力, 并且对于理论知识向来都是灌输式 教育。这在很大程度上其实体现出我校对于留学生教育还停留在过去对中国学生的传统式教 育方式中，缺乏个性化素质培养的意识形态。

在受教育阶段，人的创造性一定程度上表现为尊重个性化发展。没有个性的发展，就相 当于模子式的灌输, 中国的传统教育多是如此。但特别地, 尊重个性又绝非反对一般意义上 的普遍性教育, 而是在开展普遍性教育的基础上不否认个性, 尊重个性, 重视个性。因此, 作为高校和教师, 首先就应该纠正自己的意识形态, 正确认识个性化能力培养发展的重要性, 
然后在教学实践中积极关注留学生们的个性发展, 为学生创造平台和机会, 并给予恰当的引 导。为此, 高校可以积极了解学生们的学习需求, 丰富个性化选修课程, 增加社会实践活动 的开展次数, 满足学生们的个性化需求和综合能力的发展。此外, 还应增设一些有关中国国 情及中国文化方面的选修课, 以充实学生的知识结构, 给学生们提供一个系统性学习中国文 化的平台, 让他们更好地融入到校园中去。

\section{4 留学生管理体系游离, 应完善管理制度促进趋同化管理发展}

在中国留学生培养管理初期, 留学生群体基本都是独立于中国学生管理之外的, 由专门 的职能机构负责日常管理工作。起初, 留学生规模较小, 该模式完全能够有效地保证留学生 培养管理工作的正常开展。但是如今, 随着高等教育教育国际化的大力推进, 来华留学生规 模大幅增加, 之前的特殊化管理使得来华留学生成为高校中的特殊群体, 事无巨细的管理模 式使得管理人员工作日益繁重，并且部门间经常因为职责交叉混乱而推诿扯皮，这对传统的 管理模式提出很大的挑战。很明显, 两个学生群体逐渐产生两种管理制度, 并且制度之间逐 步分离产生两极化, 中国学生与留学生群体交流越来越少, 这样下去, 不仅不利于留学生培 养，也不利于高校国际化发展。在这种背景下，“趋同化管理”的思想应运而生。

“去异求同” 是留学生趋同化管理的目标, 但是留学生群体来自世界各国, 其语言能力、 文化背景和生活习惯各有不同, 我们需要正视这些差异, 因此需要在推进趋同化管理的过程 中以跨文化的视角坚持 “同中有异” 的原则。 ${ }^{[3]}$ 各高校应当积极构建硕士留学生趋同化管理 架构, 加强师资队伍建设, 大力促进教学过程趋同化, 加强硕士留学生入学辅导, 积极发挥 校园学生社团和自治组织优势, 加强中外学生的交流与融合。总而言之, 要从制度、教育和 文化等各方各面实现留学生的趋同化管理。

\section{5 师资水平有待提升, 应加强教师国际化教学水平培养}

面对留学生教育国际化的考验，高校教师站在了迎接挑战的紧要关头。我国高校教师现 有的素质与国际化的高校教师素质标准、与发达国家相同层次的高校教师的素质相比还有一 定的差距, 使得他们在高等教育国际化趋势下, 面对本国高等教育在人才培养目标、科学研 究、社会服务以及国际交流与合作等功能上的拓展和延伸，有些力不从心。因而当前的师资 国际化水平还是有待提升的, 不仅仅要在知识素质和科研能力上精益求精, 还应该在语言能 力、教学能力上加强培训。

因此笔者认为可以从以下两点着重加强高校整体师资水平，第一，大力推进教师语言培 训, 提高高校双语教师的比例。语言是教学过程中最基础的教学工具, 语言能力的薄弱不仅 干扰了教学工作的正常开展, 对教学质量提高也有严重的影响。为了解决这一问题, 高校可 以积极利用自身优势资源, 开展教师语言培训班等。第二, 提升高校教师的跨文化教学能力。 在面对未来国际学生汇集的文化多样性的大课堂时, 高校教师只有了解来自异域文化背景学 生的学习特点才能顺利展开教学工作。有学者认为, 让教师直接进行跨国交流并参与其教学 活动是将教育国际化落到实处的根本之举。当教师对跨文化教学的理解逐步加深时, 高校教 师才能获得内部驱动力, 逐渐修正个人传统的教学理念、教学方式和考核方式。[4]

\section{5. 结束语}

本研究以从大连理工大学来华留学硕士研究生培养现状分析出发, 通过问卷调查分析和 访谈分析, 得出影响硕士留学生培养管理满意度的七个关键因素, 并发现出来华留学硕士研 究生教育中存在的五个根源性问题。最后以大连理工大学来华留学硕士研究生培养过程中遇 到的问题为基础, 提出关于全国各高校来华留学硕士研究生培养管理的对策建议。

留学生教育有利于提升学校的国际影响力, 有利于校园文化多元化, 有利于教学科研国 际化, 更有利于教育理念国际化。留学生教育全面贯彻落实研究生教育改革精神, 进行有效 
的留学生培养改革与实践。

来华留学硕士研究生的培养关键, 在于在现有高等教育体制下处理好留学生与中国学生 之间的差异性, 在招生阶段, 合理评估高校当前的教育实际, 严格留学生入学门槛; 在培养 阶段, 正视文化差异, 科学制定培养方案, 加强教师现代化教育意识, 提高教师国际化教育 水平; 在管理过程中, 完善留学生管理体系, 大力推进留学生趋同化管理。做好这几个方面, 教育过程中的各种问题才能迎刃而解, 来华留学硕士研究生教育质量才会得到极大提高, 进 而促进我国高等教育国际化水平的提升。

\section{致谢}

本文为国家大学生创新创业训练计划项目《我国高校国际学生培养管理现状及分析一一 以大连理工大学留学生为例》(2016101410215)、国家社会科学基金重点项目《区域中心城 市绿色转型要素的协同演化研究》(14AZD090)、辽宁省省社科规划基金项目《辽宁省人才 生态环境评价研究》( L16BRK001)、教育部学校绿色发展研究基金项目《绿色校园评价》

(2016 第一期)、辽宁省社科联项目 《基于人力资源生态位的人才环境研究》(2011/s|ktglx12）大连市科技计划项目《大连市城市化进程中生态安全格局的研究》（20140122）的阶段 性研究成果之一。

\section{References}

[1] Jia Sun. the research on Validity of New HSK[D].Jilin University,2013.

[2] Linhua Zhang. A comparative study on language testing of foreign applicants between Chinese and German universities[J]. Journal of World Education,2012,(19):70-74.

[3] Honghui Yi. some thinking and practice about Assimilation management of international students in China[J]. Education Teaching Forum,2015,(38):8-9.

[4] Yin Hu. Study on Improvement of Educational Service Quality for International Students in China_-A Case Study of Xiamen University[D].Xiamen University,2014. 